\title{
KOMPENSASI DAN SISTEM KEPEMIMPINAN TERHADAP KEPUASAN KERJA KARYAWAN OUTSOURCING
}

\author{
Dwi Lestari Rahayu'), Mawarta Onida ${ }^{2)}$ \\ Jurusan Administrasi Niaga Politeknik Negeri Jakarta Email: \\ Idwita0704@gmail.com,_2mawarta.onida@bisnis.pnj.ac.id
}

\begin{abstract}
Job satisfaction is important because it has proven to be of many benefits to the interests of the public, industry and society, namely in efforts to increase production and reduce costs through improving employee attitudes and behavior. Viewed from the organization, employee job satisfaction is related to productivity, positive work behavior, controlling turnover and performance. This research was conducted by taking existing cases at PT. Bank BNI (Persero). PT. Bank BNI is a company that uses an outsourced labor system as a process of transferring business activities to third parties. The purpose of this study was to determine whether compensation and leadership systems can affect job satisfaction for outsourcing employees. The results showed that there was a strong positive correlation between compensation and leadership systems on the job satisfaction of outsourcing employees by $64 \%$ with the contribution of the independent variables of $41 \%$. The analysis of variance produces an $F$ value of 20.463> F table 3.15, which states that compensation and the leadership system together have an effect on job satisfaction of outsourcing employees. The results of the partial significance of each variable also show a significant value smaller than 0.05 and the $t$ test for each variable also produces a calculated $t$ value that is greater than the $t$ table. So it can be concluded that compensation and leadership systems have a significant effect on the satisfaction of outsourcing employees at PT. Bank BNI (Persero).
\end{abstract}

Keywords : Compensation, leadership system, job satisfaction, outsourcing

\begin{abstract}
ABSTRAK
Kepuasan kerja menjadi penting dikarenakan terbukti banyak bermanfaat bagi kepentingan umum, industri dan masyarakat yaitu dalam usaha peningkatan produksi dan pengurangan biaya melalui perbaikan sikap dan tingkah laku karyawan. Ditinjau dari organisasi, kepuasan kerja karyawan berhubungan dengan produktivitas, perilaku kerja positif, mengendalikan turn over dan kinerja. Penelitian ini di lakukan dengan mengambil kasus yang ada pada PT. Bank BNI (persero). PT. Bank BNI merupakan salah satu perusahaan yang menggunakan sistem tenaga kerja outsourcing sebagai proses mentransfer kegiatan bisnis kepada pihak ketiga. Tujuan Penelitian ini adalah untuk mengetahui apakah pemberian kompensasi dan sistem kepemimpinan dapat mempengaruhi kepuasan kerja bagi karyawan outsourcing. Hasil penelitian menunjukkan Terjadi korelasi positif yang kuat antara pemberian kompensasi dan sistem kepemimpinan terhadap Kepuasan kerja karyawan outsourcing sebesar $64 \%$ dengan besar kontribusi variabel bebas sebesar $41 \%$. Pada analysis of varian menghasilkan nilai $F$ hitung sebesar 20,463 > F tabel 3,15 menyatakan bahwa pemberian kompensasi dan sistem kepemimpinan secara bersama sama berpengaruh terhadap kepuasan kerja karyawan Outsourcing. Hasil signifikansi secara parsial masing - masing variabel juga memperlihatkan nilai signifikan lebih kecil dari 0,05 dan pada uji $t$ masing - masing variabel juga menghasilkan nilai $t$ hitung yang lebih besar dari $t$ tabel. Maka dapat diberi kesimpulan bahwa pemberian kompensasi dan sistem kepemimpinan berpengaruh nyata secara signifikan terhadap kepuasan karyawan outsourcing di PT. Bank BNI (persero).
\end{abstract}

Kata Kunci : Kompensasi, sistem kepemimpinan, kepuasan kerja, outsourcing

\section{PENDAHULUAN}

Salah satu penelitian yang cukup banyak dilakukan dan sangat penting dilakukan pada sebuah organisasi adalah mengenai kepuasan kerja karyawan. Kepuasan kerja merupakan teori klasik dalam manajemen sumberdaya manusia. Literatur tentang kepuasan kerja sudah muncul sejak pertumbuhan era industri tahun 1930-an, namun tetap masih 
diperlukan sampai saat ini. Upaya meraih kepuasan kerja sangat penting baik bagi individu maupun organisasi. Kepuasan kerja tidak hanya mendorong perilaku positif seperti produktif, disiplin, patuh, inovatif, suka menolong, (Yahyagil, 2015) Penelitian mengenai kepuasan kerja menjadi penting dikarenakan terbukti banyak bermanfaat bagi kepentingan umum, industri dan masyarakat yaitu dalam usaha peningkatan produksi dan pengurangan biaya melalui perbaikan sikap dan tingkah laku karyawan. Salah satu upaya yang dilakukan untuk meminimalkan biaya adalah dengan mempekerjakan tenaga kerja sesedikit mungkin dengan harapan agar tenga kerja dapat memberi kontribusi maksimal sesui sasaran perusahaan. Untuk itu PT BANK BNI (persero) sebagai salah satu perusahaan perbankan berstatus Badan Umum Milik Negara (BUMN) di Indonesia menggunakan karyawan tetap agar fokus dalam pekerjaan yang menjadi core business. Sedangkan pekerjaan penunjang diserahkan kepada pihak lain yang dikenal dengan isilah outsourcing.

Karyawan outsourcing adalah karyawan yang bekerja pada satu perusahaan di mana kemudian karyawan tersebut disalurkan ke perusahaan pihak ketiga sebagai perusahaan pengguna (Suwondo, 2004). Segala kewajiban dan tanggung jawab karyawan outsourcing yang tertuang di dalam perjanjian kerjasama berada di bawah perusahaan outsourcing bukan perusahaan pengguna.

Survei juga menemukan bahwa secara umum kepuasan karyawan secara signifikan meningkat oleh kepercayaan yang dibangun antar teman sekerja. Makin peka seseorang pada tujuan seputar pekerjaannya, makin besar pula komitmen individunya pada organisasi. Karyawan yang produktif lahir dari kombinasi antara kepercayaan dan dukungan. Pakar work place relationship Courtney Anderson mengatakan: "Hasil riset tersebut menegaskan betapa pentingnya kini bagi kalangan pemimpin bisnis untuk membangun kepekaan pada kepercayaan dan tujuan dalam organisasi mereka. Menjadi pemimpin yang baik dan sukses dewasa ini tidak hanya sekadar melaksanakan tugas, tetapi harus mampu menciptakan lingkungan yang mendukung anggota tim menjadi bahagia, berkomitmen dan produktif ".

Aspek kepuasan kerja akhirnya menarik untuk diteliti karena sangat bernilai dan bermanfaat baik untuk kepentingan individu maupun perusahaan. Bagi individu setidak tidaknya dapat dicari sebab dan sumber kepuasan kerja, serta upaya yang dapat dilakukan agar dapat ditingkatkan. Sedangkan bagi perusahaan, penelitian dapat dikaitkan dengan manfaat ekonomis. Misalnya dengan kepuasan kerja, perusahaan dapat menempuh berbagai langkah efisiensi, pengurangan biaya produksi atau peningkatan hasil produksi barang maupun jasa sehingga tercipta loyalitas pelanggan secara optimal. Dalam hal kondisi yang berpotensi menimbulkan konflik dan ketidakpuasan pegawai, maka dibutuhkan sistem kepemimpinan yang berperan untuk mengendalikan konflik serta dapat membangun team work yang solid, konsisten melaksanakan visi dan misi perusahaan, saling melengkapi dan saling tergantung satu dengan lainnya.

\section{Tujuan Penelitian}

Tujuan Penelitian ini adalah untuk mengetahui apakah pemberian kompensasi dan sistem kepemimpinan dapat mempengaruhi kepuasan kerja bagi karyawan outsourcing.

\section{Perumusan Masalah}

Berkaitan dengan latar belakang dan pembatasan masalah tersebut diatas, dapat dirumuskan permasalahan penelitian sebagai berikut :

1. Seberapa besar pengaruh pemberian kompensasi terhadap kepuasan kerja karyawan outsourcing? 
2. Seberapa besar pengaruh sistem kepemimpinan terhadap kepuasan kerja karyawan outsourcing ?

3. Seberapa besar pengaruh pemberian kompensasi dan sistem kepemimpinan secara bersama sama terhadap kepuasan kerja karyawan outsourcing ?

\section{Landasan Teori}

\section{Definisi Kompensasi}

Kompensasi adalah segala sesuatu yang diterima baik berupa fisik maupun non fisik. Kompensasi juga berarti seluruh imbalan yang diterima oleh seseorang pekerja/ karyawan atas jasa atau hasil dari pekerjaannya dalam sebuah perusahaan dalam bentuk uang atau barang, baik secara langsung maupun tidak langsung. Dewasa ini masalah pemberian kompensasi dipandang sebagai salah satu tantangan yang harus dihadapi oleh manajemen suatu organisasi/perusahaan.Kompensasi

tersebut tidak lagi dipandang sematamata sebagai alat pemuas berbagai kebutuhan material seseorang, tetapi terkait pula dengan harkat martabat manusia ditinjau dari sisi pandang organisasi/perusahaan, pemberian kompensasi akan selalu dikaitkan dengan kuantitas, kualitas, dan manfaat jasa yang dipersembahkan oleh karyawan bagi organisasi/perusahaan tempatnya bekerja.

\section{Faktor-Faktor yang Mempengaruhi Besarnya Kompensasi}

Besar kecilnya kompensasi tidak mungkin dapat ditentukan begitu saja, tanpa mengantisipasi perkembangan keadaan sekitar yang mengelilingi gerak perusahaan. Penetapan kompensasi yang hanya berdasarkan keinginan sepihak saja tanpa didasarkan pada perhitunganperhitungan yang rasional dan bisa dipertanggungjawabkan secara yuridis akan sulit diterapkan dalam jangka panjang. Karena itu, ada anggapan bahwa besar kompensasi akan selalu dipengaruhi oleh beberapa faktor diantaranya.

1. Produktivitas

2. Kemampuan untuk membayar

3. Kesediaan untuk membayar

4. Suplai dan permintaan tenaga kerja

5. Organisasi karyawan

6. Berbagai peraturan dan perundangundangan.

Hal yang senada juga dikemukakan oleh Robbins (2013) yang mengemukakan bahwa penghargaan dapat meningkatkan prestasi kerja dan kepuasan kerja apabila mereka merasakan keadilan dalam penggajian, penghargaan yang mereka terima dikaitkan dengan kinerja mereka, dan berkaitan dengan kebutuhan individu.

\section{Definisi Sistem Kepemimpinan}

Sistem kepemimpinan adalah kegiatan atau seni mempengaruhi orang lain agar mau bekerja sama yang didasarkan pada kemampuan orang tersebut untuk membimbing orang lain dalam mencapai tujuan yang diinginkan kelompok.

Kepemimpinan merupakan suatu usaha mempengaruhi orang, antar perorangan (interpersonal), lewat proses komunikasi untuk mencapai sesuatu atau beberapa tujuan" (Perdana, 2011: 263). Hal ini menunjukkan bahwa pola mempengaruhi karyawan atau orang lain,

\section{Definisi Kepuasan Kerja}

Kepuasan kerja merupakan sikap (tindakan-kognisi), perasaan senang (ungkapan-afeksi), atau kesenjangan (gab) antara apa yang telah diperoleh dengan apa yang diharapkan. Sikap senang yang ditunjukkan oleh seseorang dalam bekerja merupakan ekspresi karena apa yang menjadi tanggungjawabnya telah dijalankan dengan baik dan merasa puas atas hasil kerjanya. Sebaliknya apabila seseorang dalam bekerja tidak didukung oleh peralatan kerja yang memadai, lingkungan kerja yang tidak kondusif, dan rendahnya perhatian dari pimpinan, 
maka hal itu akan menimbulkan ketidakpuasan kerja. Ketidakpuasan pegawai di tempat kerja dikatakan oleh (Robin \& Judge, 2013) dapat mengarah pada tindakan keluar-meninggalkan organisasi, suara-aktif konstruktif, kesetiaan pasif optimis, dan pengabaianpasif mengabaikan perintah dan larangan Kepuasan kerja adalah keadaan emosional yang menyenangkan yang dialami seorang individu yang didasarkan atas adanya penilaian bahwa suatu pekerjaan memberikan nilai (values) tertentu. Sedangkan ketidakpuasan kerja didefinisikan sebagai keadaan emosional yang tidak menyenangkan yang dirasakan seorang individu yang didasarkan atas adanya penilaian bahwa suatu pekerjaan menghambat dia untuk mencapai nilainilai (values) tertentu atau pekerjaan itu tidak mempunyai nilai (value) sama sekali. Berdasarkan definisi terdapat dua kata kunci dalam definisi kepuasan kerja, yaitu emosi (emotion) dan nilai (values). Emosi didefinisikan sebagai bentuk psychosomatic dimana seorang individu mengalami suatu kejadian yang menyenangkan atau tidak menyenangkan dari apa yang diharapkan sebelumnya terhadap beberapa aspek dalam realitas hidup.

Locke (1969), menggarisbawahi bahwa proses penilaian seorang individu terhadap suatu pekerjaan baik pekerjaan yang menyenangkan maupun tidak menyenangkan didasarkan pada 3 (tiga) elemen, yaitu:

(1) Persepsi terhadap satu atau beberapa aspek dalam suatu pekerjaan;

(2) Standar nilai individu, secara implisit maupun eksplisit;

(3) Penilaian terhadap kesenjangan antara persepsi dan nilai.

Definisi lainnya berkaitan dengan kepuasan kerja diajukan oleh Kuswandi (2005), mendefinisikan kepuasan kerja sebagai respon psikologis seseorang secara multidimensional terhadap suatu pekerjaan. Respon psikologis individual ini meliputi respon kognitif (cognitive evaluation), respon afektif (emotional reactions), dan komponen keperilakuan (behavioral component). Aspek konitif dari kepuasan kerja menggambarkan keyakinan individu terhadap pekerjaan atau situasi pekerjaannya. Sabagai contoh, seorang individu mungkin akan memiliki keyakinan bahwa pekerjaannya menarik, menstimulir, membosankan. Aspek afektif dari kepuasan kerja merupakan reaksi emosional (emotional reaction) seorang individu terhadap suatu pekerjaan. Reaksi emosional ini muncul dari adanya perbandingan antara outcome yang sesungguhnya diterima dan outcome yang diharapkan /diinginkan. Sedangkan komponen keperilakuan (behavioral component) menggambarkan perilaku atau kecenderungan perilaku individu terhadap pekerjaannya.

Berdasarkan komponen keperilakuan, tingkat kepuasan kerja seorang individu mungkin dapat ditunjukkan oleh kesungguhan dalam bekerja, keteraturan dalam bekerja, atau bahkan kesedian untuk bekerja dalam jangka waktu yang lama.

\section{Definisi Outsourcing}

Outsourcing merupakan penggunaan tenaga kerja dari pihak ketiga untuk menyelesaikan suatu pekerjaan. Perusahaan outsourcing merupakan perusahaan yang menyediakan jasa dan menyalurkan tenaga kerja dengan keahlian tertentu ke perusahaan yang membutuhkan. Penyerahan pekerjaan dilakukan atas dasar perjanjian kerja sama operasional antara perusahaan pemberi kerja (principal) dengan perusahaan penerima pekerjaan (perusahaan outsourcing).

Dalam pengertian umum, istilah outsourcing diartikan sebagai contract (workout). Outsourcing dipandang sebagai tindakan mengalihkan beberapa aktivitas perusahaan dan hak 
pengambilan keputusannya kepada pihak lain ( outside provider), di mana tindakan ini terkait dalam suatu kontrak kerjasama. Dapat juga dikatakan outsourcing sebagai penyerahan kegiatan perusahaan baik sebagian ataupun secara menyeluruh kepada pihak lain yang tertuang dalam kontrak perjanjian. Ada tiga unsur penting dalam outsourcing, yaitu:

1. Terdapat pemindahan fungsi pengawasan,

2. Ada pendelegasian tanggung jawab/tugas suatu perusahaan,

3. Dititik beratkan hasil/output yang ingin dicapai oleh perusahaan.

Penyerahan tanggung jawab kegiatan perusahaan kepada pihak ketiga sebagai pengawas pelayanan yang telah disepakati. Penyerahan kegiatan, tugas ataupun pelayanan pada pihak lain, dengan tujuan untuk mendapatkan tenaga ahli serta meningkatkan efesiensi dan efektivitas perusahaan.

\section{METODE PENELITIAN}

\section{Jenis dan Sumber Data}

Jenis Data

Jenis data yang digunakan adalah:

a. Data Kualitatif, berupa hasil wawancara dan referensi dari buku-buku yang terkait dengan penelitian.

b. Data kuantitatif didapat dari hasil pembagian angket Linkert kepada beberapa karyawan outsourcing divisi LNC PT. Bank Negara Indonesia (Persero)

\section{Sumber Data}

Sumber data yang digunakan adalah:

a. Data Primer, diperoleh dari Kantor PT. Bank Negara Indonesia (Persero) Tbk berdasarkan hasil observasi dan wawancara langsung dengan pimpinan dan karyawan outsourcing mengenai faktor faktor kepuasan kerja karyawan.

b. Data Sekunder, diperoleh melalui dokumen-dokumen perusahaan yang ada relevansinya dengan penelitian.

\section{Metode Analisis}

Metode analisis data yang digunakan dalam penelitian ini yaitu analisis statistik deskriptif. Menurut Sugiyono (2014), statistik deskriptif adalah statistik yang digunakan untuk menganalisa data dengan cara mendeskripsikan atau menggambarkan data yang telah terkumpul sebagaimana adanya tanpa bermaksud membuat kesimpulan yang berlaku umum atau generalisasi. Data di olah menggunakan regresi linier berganda melalui aplikasi spss

\section{Deskripsi Data}

Jumlah seluruh karyawan outsourcing Unit LNC Jakarta. PT. Bank BNI (Persero) Tbk. adalah 166 orang. Diambil untuk responden sebanyak 62 responden (hasil yang didapat berdasarkan rumus slovin)

\section{Jenis Kelamin Responden}

Jenis kelamin responden pada peneitian ini adalah sebagai berikut :

Tabel.1: Data Jenis Kelamin outsourcing (responden)

\begin{tabular}{|c|c|c|c|}
\hline $\mathrm{NO}$ & USIA & JUMLAH & PERSENTASE \\
\hline 1 & Laki - Laki & 33 orang & $53,2 \%$ \\
\hline 2 & Perempuan & orang & $46,8 \%$ \\
\hline & Jumlah & orang & $100 \%$ \\
\hline
\end{tabular}

Sumber data : Dokumentasi Bank

\section{Usia Responden}

Usia responden pada penelitian ini adalah sebagai berikut :

Tabel. 2: Data Usia outsourcing

\begin{tabular}{ccrrcc}
\hline NO & \multicolumn{1}{l}{ USIA } & & JUMLAH & PERSENTASE \\
\hline 1 & $18-22$ thn & 13 orang & $21 \%$ \\
2 & $23-27$ thn & 26 orang & $42 \%$ \\
3 & $28-32$ thn & 15 orang & $24 \%$ \\
4 & $>32$ th & 8 orang & $13 \%$ \\
\hline \multicolumn{2}{c}{ Jumlah } & $\mathbf{6 2}$ orang & $\mathbf{1 0 0} \%$ \\
\hline
\end{tabular}

Sumber data : Dokumentasi Bank

\section{Pendidikan Responden}

Latar belakang pendidikan pada peneltian ini dikelompokkan ke dalam beberapa kelompok. Uraian lebih rincinya adalah sebagai berikut : 
Tabel. 3: Data Pendidikan Terakhir

Responden

\begin{tabular}{ccrlcc}
\hline NO & $\begin{array}{c}\text { PENDIDIKAN } \\
\text { TERAKHIR }\end{array}$ & \multicolumn{2}{c}{ JUMLAH } & PERSENTASE \\
\hline 1 & SLTA & 5 & orang & 8 & $\%$ \\
2 & D1, D2, D3 & 25 & orang & 40 & $\%$ \\
3 & Sarjana & 32 & orang & 52 & $\%$ \\
\hline & Jumlah & $\mathbf{6 2}$ & orang & $\mathbf{1 0 0}$ & $\%$ \\
\hline
\end{tabular}

Sumber data : Dokumentasi Bank

\section{HASIL DAN PEMBAHASAN}

Data yang dikumpulkan dalam penelitian ini diperoleh dari hasil angket yang terdiri dari tiga variabel, yaitu variabel Pemberian Kompensasi (X1), Sistem Kepemimpinan (X2) dan Kepuasan Kerja karyawan Outsourcing (Y). Program yang digunakan untuk menganalisis Data yang dikumpulkan kemudian diolah menggunakan aplikasi spss..

Tabel.4 : Nilai Koefisien Determinasi Analisis Regresi Berganda

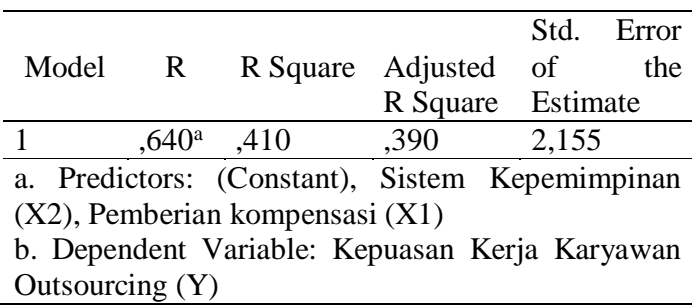

Pada tabel di atas diperoleh nilai $\mathrm{R}=$ 0,640 artinya terjadi hubungan korelasi positif antara variabel pemberian kompensasi dan sistem kepemimpinan dengan kepuasan kerja karyawan outsourcing sebesar $64 \%$. Nilai koefisien determinasi sebesar 0,410 menunjukkan bahwa besarnya kontribusi pengaruh variabel kompensasi (X1) dan sistem kepemimpinan (X2) dengan Kepuasan Kerja Karyawan Outsourcing (Y) sebesar $41 \%$.
Tabel 5.: Analysis of Varian

\begin{tabular}{|c|c|c|c|c|c|c|}
\hline & Model & $\begin{array}{l}\text { Sum of } \\
\text { Square }\end{array}$ & $\mathrm{df}$ & $\begin{array}{c}\text { Mean } \\
\text { Squar } \\
\text { e }\end{array}$ & F & Sig \\
\hline \multirow[t]{3}{*}{1} & Regression & 189,992 & 2 & $\begin{array}{l}94,99 \\
6\end{array}$ & \multirow[t]{3}{*}{$\begin{array}{l}20,4 \\
63\end{array}$} & \multirow[t]{3}{*}{, $000^{\mathrm{b}}$} \\
\hline & Residual & 273,895 & 59 & \multirow[t]{2}{*}{4,642} & & \\
\hline & Total & 463,887 & 61 & & & \\
\hline \multicolumn{7}{|c|}{$\begin{array}{l}\text { a. Dependent Variable: Kepuasan Kerja Karyawan } \\
\text { Outsourcing (Y) } \\
\text { b.Predictors: (Constant), Sistem Kepemimpinan (X2), } \\
\text { Pemberian kompensasi (X1) }\end{array}$} \\
\hline
\end{tabular}

Pada tabel diatas menunjukkan pengujian simultan untuk model regresi yang melibatkan ketiga ariabel penelitian X1, X2 dan Y. Dari hasil pengujian diperoleh nilai F hitung sebesar 20,463 > dari nilai $F$ tabel 3,15 menandakan adanya pengaruh secara bersama sama antara X1 dan X2 terhadap $\mathrm{Y}$ dengan nilai signifikan (sig) sebesar 0,000. Karena hasil signifikan < 0,05 maka dapat dinyatakan bahwa pemberian kompensasi dan sistem kepemimpinan memiliki pengaruh nyata terhadap kepuasan karyawan outsourcing.

Tabel 6:. Nilai Koefisien Regresi Berganda

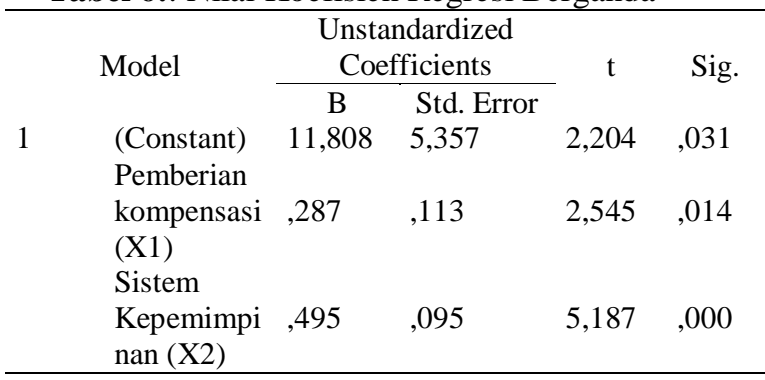

Tabel diatas merupakan hasil output dari nilai koefisien Regresi berganda, pada kolom coefficient menunjukkan pengujian secara parsial dengan uji t.

a. Hasil pengujian untuk variabel pemberian

kompensasi diperoleh nilai koefisien sebesar 0,287 dan $t$ hitung sebesar $2,545>\mathrm{t}$ tabel 2,00 atau nilai sig. sebesar $0,014<0,05$ maka dengan tingkat kesalahan 5\% dapat dinyatakan bahwa secara parsial pemberian kompensasi $(\mathrm{X})$ berpengaruh nyata terhadap kepuasan kerja karyawan outsourcing. 
b.Hasil pengujian untuk variabel sistem kepemimpinan (X2) diperoleh nilai koefisien sebesar 0,495 dan t hitung sebesar 5,187 $>\mathrm{t}$ tabel 2,00 atau nilai sig. sebesar 0,000 <0,05 maka dengan tingkat kesalahan 5\% dapat dinyatakan bahwa secara parsial sistem kepemimpinan (X2) berpengaruh nyata terhadap kepuasan kerja karyawan outsourcing. Dari hasil output pada tabel diatas dapat dibuat persamaan regresi sebagai berikut :

$Y=11,808+0,287 X 1+0,495 X 2$.

Berarti setiap kenaikan 1 nilai pada pemberian kompensasi akan meningkatkan kepuasan kerja karyawan outsourcing sebesar 0,287 dan setiap kenaikan 1 nilai pada sistem kepemimpinan akan meningkatkan kepuasan kerja karyawan outsourcing sebesar 0,495

\section{KESIMPULAN}

1 Pemberian Kompensasi dan sistem kepemimpinan memiliki korelasi (hubungan) positif terhadap Kepuasan Kerja Karyawan Outsourcing sebesar $64 \%$ dengan tingkat hubungan yang kuat (60 \% 79\%). Sedangkan besarnya kontribusi variabel pemberian kompensasi dan sistem kepemimpinan terhadap kepuasan kerja karyawan outsourcing hanya sebesar $41 \%$ saja, sisa nya sebesar $59 \%$ adalah variabel lain yang merupakan faktor - faktor kepuasan kerja lain yang tidak dibahas dalam penelitian ini.

2. Niilai signifikan yang dihasilkan pada analisis of varian adalah 0,000 berarti < 0,05 menandakan bahwa kedua variabel yaitu pemberian kompensasi dan sistem kepemimpinan memiliki pengaruh nyata terhadap kepuasan karyawan outsourcing.
3. Secara parsial masing masing variabel bebas memiliki pengaruh yang nyata terhadap variabel terikatnya. Ditandai dengan hasil signifikansi keduanya lebih kecil dari 0,05 pada tingkat kesalahan 5\%.

Berdasarkan seluruh uraian yang disajikan diatas, maka kesimpulan yang dapat diperoleh adalah ada pengaruh yang signifikan antara Pemberian Kompensasi dan Sistem Kepemimpinan terhadap Kepuasan Kerja Karyawan Outsourcing PT. Bank BNI (Persero) Tbk, Unit LNC Jakarta.

\section{DAFTAR PUSTAKA}

[1] Kuswandi. 2005.Cara Mengukur Kepuasan Karyawan. Jakarta: Elex Media Komputindo

[2] Locke, E. A. 1969. W h a t is Job Satisfaction? Organizational Behavior And Human Performance, 336, 309-336.

[3] Perdana, Yudha, Dika. 2011. "Pengaruh Motivasi Kerja Kepemimpinan dan Kesempatan Pengembangan Karir Terhadap Kinerja Karyawan di PT. Nyonya Mener Semarang”. Skripsi Universitas Diponegoro

[4] Robin, S. P., \& Judge, T. A 2013. Organizational behavior (15th ed.). New Jersey: Pearson Education, Inc., Prentice Hall

[5] Sugiyono. 2014. Metode Penelitian Bisnis (Pendekatan Kuantitatif, Kualitatif dan R\&D). cetakan keenambelas. Bandung: Alfabeta

[6] Suwondo, Chandra. 2004. Outsourcing Implementasi di Indonesia. Jakarta : Elex Media Komputindo.

[7] Yahyagil, M. Y. 2015. Values, feelings, job satisfaction and wellbeing: the Turkish case. Management Decision, 53(10). 
[8] Https://www.linkedin.com/pulse/20 $\begin{array}{lll}14 \quad 09100 \quad 21515-154884582 & -\end{array}$ evaluasi-kinerja perusahaan

[9] Https://annisamardiana.wordpress.c om /2012/10/27/sistem-outshorcing-diindonesia 